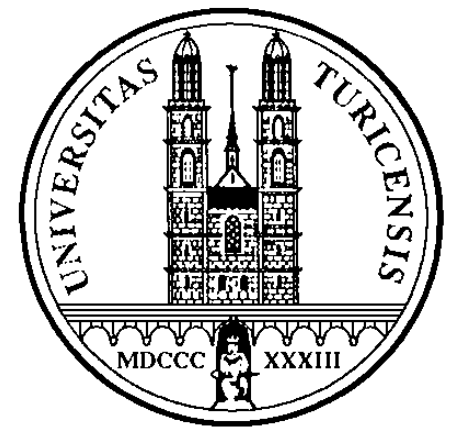

Institute for Empirical Research in Economics

University of Zurich

Working Paper Series

ISSN 1424-0459

Forthcoming: Handbook of Experimental Economic Results

Working Paper No. 43

Intertemporal Choice under Habit Formation

Ernst Fehr and Peter K. Zych

May 2000 


\title{
Intertemporal Choice under Habit Formation
}

\author{
Ernst Fehr and Peter K. Zych*
}

First version: June 1997

This version: June 1998

\section{Forthcoming: Handbook of Experimental Economic Results}

\begin{abstract}
Many of the most important choices in people's lives have an inter-temporal dimension, i.e., these choices are associated with a flow of benefits or costs that accrue in the future. In addition, such choices are frequently habit-forming. Yet, little is known about habitforming inter-temporal choice behavior.

This paper reports the results of an inter-temporal choice experiment with habit-formation. Subjects' choices deviate systematically from individually optimal decisions in the direction of over-consumption. This over-consumption is partly driven by loss avoidance, comparable to a real life situation in which addicted people consume addictive substances only in order to overpower withdrawal symptoms. Our results thus reject the theory of rational addiction.
\end{abstract}

\footnotetext{
*Fehr: Institute for Empirical Economic Research, University of Zürich, Blümlisalpstr. 10, CH-8006 Zürich, Switzerland, Tel.: +41-1-634-3709, Fax: +41-1-634-4907, E-mail: efehr@iew.unizh.ch; Zych: Institute of Economics, University of Technology, Vienna, Argentinierstr. 8, A-1040 Vienna, Austria, Tel.: +43-1-588014449, Fax: +43-1-5043203, E-mail: pkzych@pop.tuwien.ac.at.
} 


\section{Introduction}

The fundamental question addressed in this research is the degree to which models of optimal intertemporal choice are good descriptions of non-interactive individual intertemporal behavior in the presence of habit formation. The papers by Fehr and Zych (1995, 1998) provide the first laboratory examination of this question. This paper presents a short overview about the most important results of these two papers. For further details the interested reader should consult the original papers.

Many decisions in real life have an intertemporal dimension because they involve flows of future costs and benefits. Moreover, many important activities are habit forming in the sense that past activity levels affect present and future tastes for this or related activities. Most work in the economics of intertemporal choice assumes that agents behave as if they solve the intertemporal problem optimally (e. g. Deaton 1992, Browning and Lusardi 1996, Romer 1996). For a broad class of intertemporal decision problems optimal behavior has to satisfy Bellman's principle of optimality. Unfortunately, Bellman's principle per se has no empirically testable content unless one is willing to impose strong a priori identifying restrictions on the functional forms of agents' preferences and beliefs (Rust 1994). Outside the laboratory the researcher does, in general, neither know agents' preferences nor agents' beliefs about random variables. However, in the laboratory the researcher has control over preferences and beliefs which allows for rigorous tests of intertemporal models. This renders experimental methods very useful in this area of research.

\section{Experimental Design}

For our experiment we used a perfectly isomorphic implementation of the "Model of Rational Addiction" by Becker and Murphy (1988) with a time horizon of 30 periods. The experimental instructions were framed in neutral terms to avoid associations with addictive goods, which would have led to a loss of control over the subjects' preferences. Subjects' task in the experiment was to transform the endowment ("points"; these points were of no value after the experiment) into utility ("Guilders") by buying "goods." Table 1 summarizes the implementation and the design.

\section{Table 1}

Figure 1 shows the optimal consumption path for the parameters used. By comparing the optimal consumption path with subjects actual choices we can directly test the predictions of the model. 


\section{Results}

25 undergraduate students of business administration from the University of Vienna participated in the two sessions of this experiment. Since there were no statistically significant differences in the results of the two experimental sessions we pooled the data.

Result 1: The experimental data do not support the "Theory of Rational Addiction". In fact, mean consumption is characterized by significant and stable overconsumption during the first 20 periods. Thereafter, overconsumption declines gradually and vanishes towards the end.

\section{Figure 2}

Support: Figure 2 shows the difference between the actual consumption and the conditionally optimal consumption (i.e. the optimal consumption decision conditional on the previous consumption history) together with the $95 \%$ confidence band. The figure reveals that the deviations from optimality are not randomly distributed around zero but very systematic. We can observe stable overconsumption that vanishes only towards the end of the experiment.

Result 2: Not only the aggregate data but also the individual data show that only a small number of individual consumption decisions can be labeled as "optimal". The majority of individual decisions is characterized by overconsumption.

\section{Figure 3}

Support: From a total of 1,500 decisions ${ }^{1}$ only $13 \%$ (193 decisions) are optimal, $18 \%$ (271) are characterized by underconsumption, and in $69 \%$ (1036) of the cases overconsumption occurs. In Figure 3 we have split individual decisions into three groups: overconsumption, optimal consumption, and underconsumption. As one can see, except for the last period, about $70 \%$ of individual decisions are characterized by overconsumption whereas the share of optimal decisions is rather small and diminishes over time. This high and stable overconsumption corroborates the presumption that deviations from the conditionally optimal path are driven by systematic forces. In our experiment past overconsumption may well lead to a situation in which the conditionally optimal decision involves a temporary loss. From many experiments (e.g. Tversky and Kahneman 1992) it is well known that loss aversion is a behaviorally relevant phenomenon. Here, loss aversion implies that subjects whose optimal decision requires to incur a loss tend to avoid or reduce this loss by consuming too much. This conjecture is confirmed by

${ }^{1} 25$ participants à 2 sessions à 30 periods. 
Result 3: If the optimal consumption decision implies a temporary loss nearly all decisions are characterized by overconsumption.

Support: If the utility in period $t$ gained from an optimal consumption decision in period $t$ was positive, underconsumption (260 decisions) was slightly more frequent than overconsumption (180 decisions). In contrast, there are huge differences in case that the optimal choice is associated with temporary losses: If the conditionally optimal choice implies a loss $98.8 \%$ of the non-optimal decisions are characterized by overconsumption (856 decisions) whereas only $1.2 \%$ of individual decisions exhibit underconsumption (11 decisions). For roughly 75 percent of the overconsumption decisions consumption was sufficiently high to render the temporary utility positive. This suggests that loss avoidance was an important determinant of individual decisions that stabilized overconsumption at high levels.

\section{Conclusions}

We have shown that in the presence of habit forming goods intertemporal choices deviate systematically from individually optimal decisions in the direction of overconsumption. This overconsumption was partly driven by loss avoidance, comparable to a real life situation in which addicted people consume addictive substances only in order to overpower withdrawal symptoms.

The existence of loss avoidance does, however, not explain why subjects consume too much in the first few periods. We conjecture that overconsumption during the first periods is driven by cognitive limitations. If subjects are unable to compute the aggregate present value of future costs which is associated with each level of consumption they face a form of subjective uncertainty. Hence, psychologically relevant features of the decision problem play an important role. In our context the fact that the present benefits of consumption are relatively large, immediately available and, thus, unambiguously given is likely to be of psychological relevance because it renders present benefits highly salient. In contrast, the fact that future costs per period are relatively small, distributed over time and, thus, subjectively of ambiguous size renders them much less salient. It may well be that this creates a biased perception, that is, an cognitive undervaluation of the aggregate present value of future costs relative to present benefits that gives rise to overconsumption. 


\section{References}

Becker, Gary S. and Murphy, Kevin M. (1988); "A Theory of Rational Addiction," Journal of Political Economy, 96, 675-700.

Browning, Martin and Lusardi, Annamaria (1996); "Household Saving: Micro Theories and Micro Facts", Journal of Economic Literature, Vol. 34, No. 4, 1797-1855.

Deaton, Angus (1992); Understanding Consumption, Clarendon Press, Oxford.

Fehr, Ernst and Zych, Peter K. (1995); "Die Macht der Versuchung - Irrationaler Überkonsum in einem Suchtexperiment", Zeitschrift für Wirtschafts- und Sozialwissenschaften, 115. Jahrgang, Heft 4, 569-604.

Fehr, Ernst and Zych, Peter K. (1998); "Do addicts behave rationally?", The Scandinavian Journal of Economics, forthcoming.

Romer, David (1996); Advanced Macroeconomics; McGraw-Hill Companies, New York.

Rust, John (1994); "Do People Behave according to Bellman's Principle of Optimality?", Manuscript, University of Wisconsin.

Tversky, Amos and Kahneman, Daniel (1992); "Loss Aversion in Riskless Choice: A Reference Dependent Model", Quarterly Journal of Economics, Vol. 106, 1039-1062. 
Table 1: The experimental implementation of the Becker-Murphy theory of rational addiction.

\section{THEORETICAL MODEL}

\section{EXPERIMENTAL IMPLEMENTATION}

\section{Defined as points}

Points-account with possibility to save and borrow

"Buying" goods (for a given price in points)

\begin{tabular}{|c|c|}
\hline Stock of consumption & Stock of goods \\
\hline Utility function & $\begin{array}{c}\text { A "transformation scheme" that transfers the number of } \\
\text { goods bought into an experimental currency called } \\
\text { Guilders. The exchange rate between real money and } \\
\text { Guilders is publicly known. The "transformation } \\
\text { scheme" was presented in matrix form. }\end{array}$ \\
\hline
\end{tabular}

\begin{tabular}{|c|c|}
\hline Discounting & $\begin{array}{c}\text { Guilders-account with rate of time preference as } \\
\text { interest rate }\end{array}$ \\
\cline { 2 - 3 }
\end{tabular}

\begin{tabular}{|c|} 
Perfect information \\
\cline { 2 - 2 }
\end{tabular}

Time horizon 30 periods 


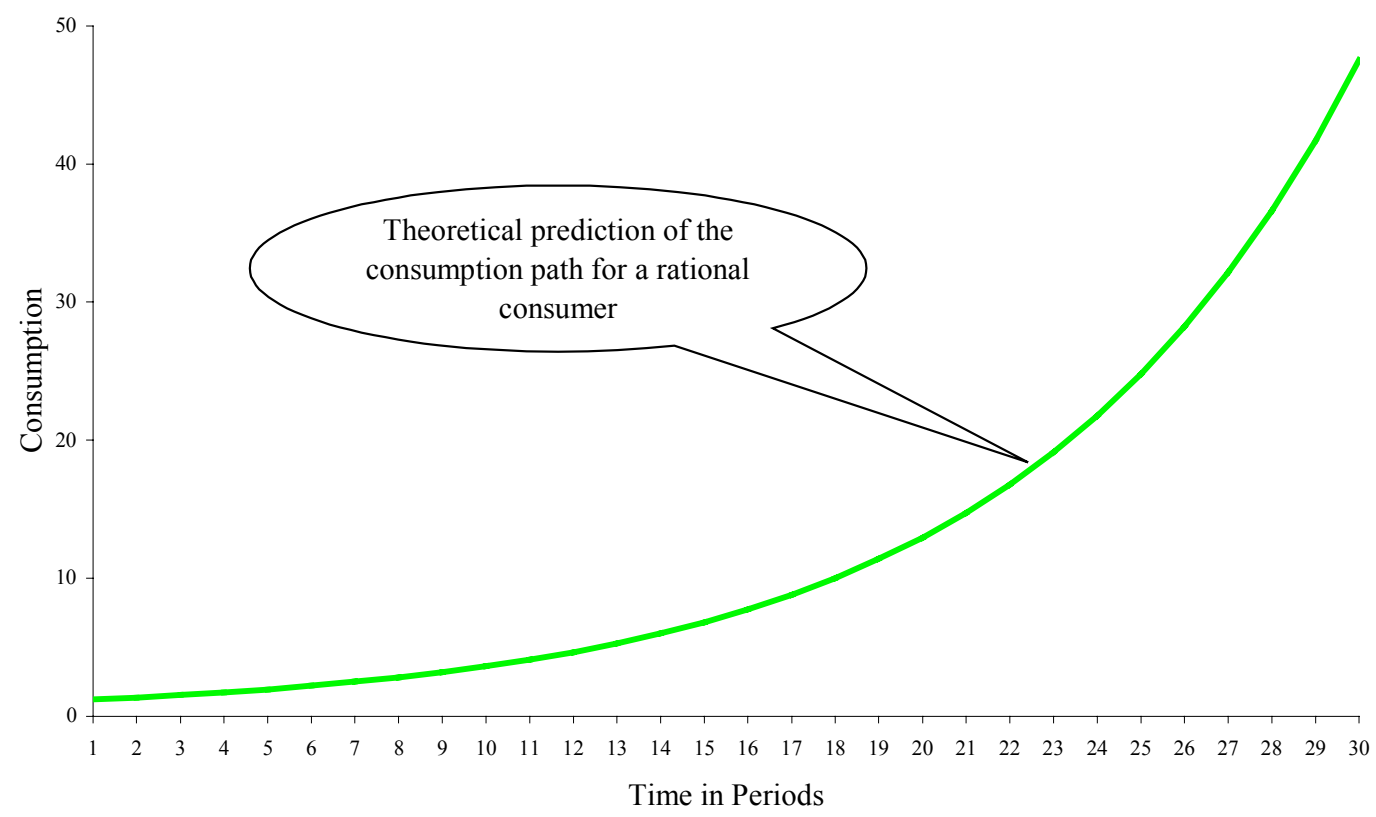

Figure 1: Optimal consumption of a habit forming good for a rational, utilitymaximizing consumer. 


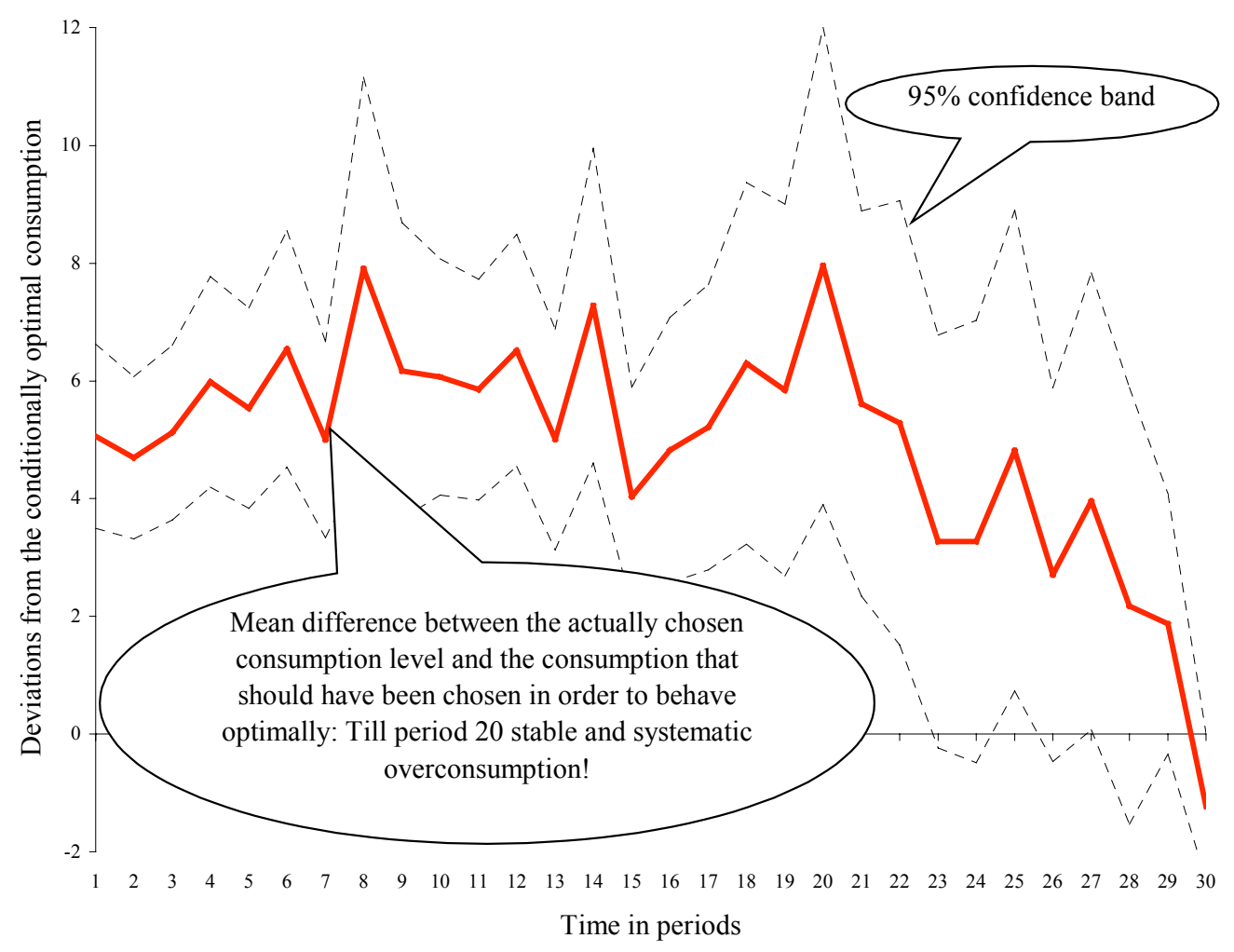

Figure 2: Experimental test of the "Theory of Rational Addiction": The model can be rejected as a correct representation of the experimental data. Actual mean consumption is characterized by significant and stable overconsumption during the first 20 periods. Thereafter, overconsumption declines gradually and vanishes towards the end. 


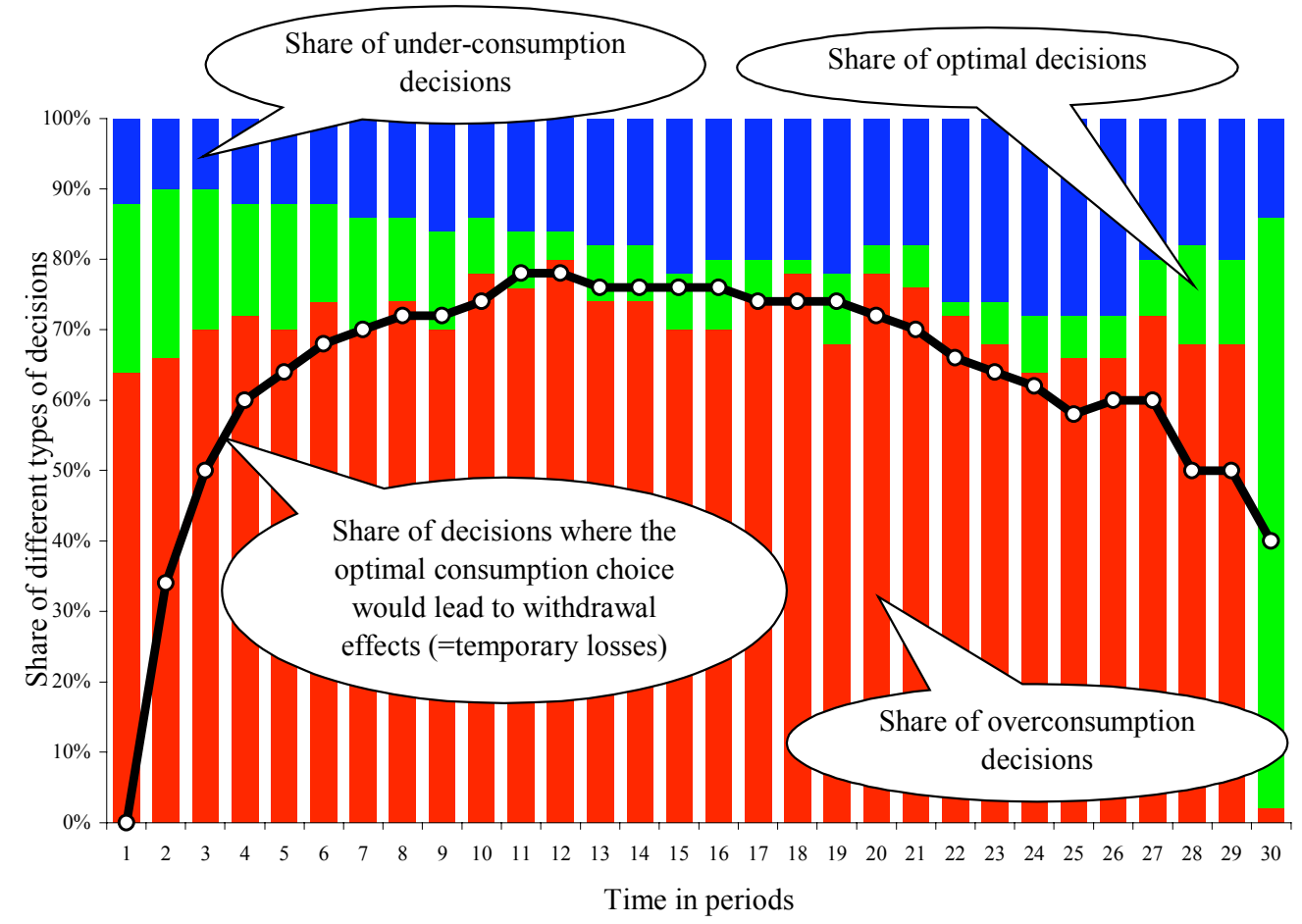

Figure 3: This graph shows for each period the share of the consumption decisions that exhibit over-, under-, or optimal consumpiton. The overwhelming share of decisions is characterized by overconsumption (around $70 \%$ ). This overconsumption is driven by loss avoidance: If the optimal choice would imply a temporary utility loss, $98.8 \%$ of the non-optimal decisions exhibit overconsumption. The black line indicates the share of optimal decisions that would result in temporary losses ("withdrawal effects"). 